\title{
Having Fun in the Heat Transfer Classroom
}

\author{
Sebastiao R. Ferreira', Leopoldo A. O. Rojas ${ }^{2}$ \\ ${ }^{1}$ Department of Chemical Engineering, University Federal of Rio Grande do Norte, Natal, Brazil \\ ${ }^{2}$ Department of Chemical Engineering, University Federal of Paraíba, João Pessoa, Brazil \\ Email:Ferreira@eq.ufrn.br, seba@ufrnet.br,leopoldoalcazar@hotmail.com
}

How to cite this paper: Ferreira, S. R., \& Rojas, L. A. O. (2017). Having Fun in the Heat Transfer Classroom. Creative Education, 8, 33-54.

http://dx.doi.org/10.4236/ce.2017.81004

Received: December 12, 2016

Accepted: January 13, 2017

Published: January 16, 2017

Copyright $\odot 2017$ by authors and Scientific Research Publishing Inc. This work is licensed under the Creative Commons Attribution International License (CC BY 4.0).

http://creativecommons.org/licenses/by/4.0/

\begin{abstract}
In this article, we discuss the possibility of starting heat transfer coursework with transient problems. We begin with the analysis of a microscopic transient problem, from when the process begins until it reaches a steady state. In addition, we propose that the students perform four or five activities per month in the classroom, in pairs, instead of requiring traditional exams. We developed a questionnaire to check the level of student satisfaction with the methodology used. Of the students, 59\% had little difficulty understanding the theory, 59\% did not have difficulty calculating microscopic transient balances, and 46\% had no difficulty with steady-state calculations. A total of 59\% preferred that all the evaluations were conducted as activities in the classroom, and $41 \%$ and $51 \%$ preferred that the course began with transient and steady-state problems, respectively.
\end{abstract}

\section{Keywords}

Teaching in the Classroom, Heat Transfer, Teaching Methodology, Transient Problem

\section{Introduction}

Energy transfer is one of the most important courses in chemical engineering. In this course, many concepts of transport phenomena are analyzed. Transport phenomena are commonly divided into energy, mass and momentum transfer (Bird, Stewart, \& Lighfoot, 2002; Bird, Stewart, Lightfoot, \& Klingenberg, 2014). In our chemical engineering department, the energy transfer course is still denominated Heat Transfer.

The academic laboratories are used to complement and reinforce the theoretical teaching imparted during lectures in a practical way. Stammitti (2013) selected three laboratory experiments on transport phenomena (metallic bar temperature profiles, transient heat conduction and the performance of fixed and fluidized bed reactors) and developed an Excel spreadsheet for each experiment. 
Fifteen chemical engineering students who made use of those spreadsheets were surveyed, and the results showed that such spreadsheets were useful for reducing the workload and increasing the quality of the analysis because the students had the opportunity to verify their experimental results with several correlations and models (Stammitti, 2013).

Vega, Portillo, Cano, \& Navarrete (2014) proposed and implemented a new problem-based learning methodology in a laboratory-based course in the chemical engineering degree program at the Superior Technical School of Engineering at the University of Seville, Spain. Based on small group work and problembased learning, they proposed new challenges and opportunities for the development of competences in engineering students. The students developed tasks involving process design, selection of alternatives, decision-making, basic engineering design and purchasing management that concluded with the assembly and activation of a laboratory-scale distillation unit. The methodology allowed students to work on all the competences linked to the course with a high degree of participation and motivation. Vega, Portillo, Cano, \& Navarrete (2014) concluded that the tool used was attractive and useful for incorporation into laboratory-based courses in chemical engineering.

Regalado-Méndez, Cid-Rodríguez, \& Báez-González (2010) and RegaladoMéndez, Peralta-Reyes, \& Báez-González (2011) developed a competency-based learning methodology that includes a horizontal and vertical crossword puzzle containing concepts from thermodynamics, principles of heat transfer, general systems theory and differential equations. In addition, they designed a questionnaire to evaluate the attitude and knowledge of the students; it consists of three types of evaluation: self, homogeneous and heterogeneous. They found that most students demonstrated good predispositions and improved acquisition of knowledge. They consider the methodology appropriate for increasing global understanding in the teaching-learning process.

Although research suggests that teaching methods involving active learning are more effective (Lund, 2008; 2009), most engineering courses are still taught using the traditional lecture. On his website, Lund (2016) claims that he decided to change the format of a course denominated Kinetics and Reaction Engineering. He now gives lectures in which the students spend a large part of their time learning activities. He created teaching resources that he presents on his website and hopes they help others to do something similar.

We lead the heat transfer course in the Department of Chemical Engineering at the Federal University of Rio Grande do Norte, Brazil, in a laboratory with computers for students and professors to perform calculations and/or teach the theoretical part of the course. In addition, other professors teach transport phenomena in traditional laboratories and include experiments on heat, mass and momentum transfer. Ganley (2015) used numerical simulations in the reactor design laboratory and concluded that the overall quality of the students' work was very good and that, in general, the students do not have difficulty discussing the results of their experimental work. Computer-aided design has become pop- 
ular and useful in class, which increases the analysis capacity in all areas of engineering (Cartaxo, Silvino, \& Fernandes, 2014).

Some authors begin courses on transport phenomena with microscopic balances (Bird, Stewart, \& Lighfoot, 2002; Slattery, 1999), whereas, for example, Welty, Wickes, \& Wilson (1969) begin with macroscopic balances, and Akker \& Mudde (2014) present macroscopic balances in their first chapter. During the past 19 years, we have given heat transfer lectures to undergraduates in the chemical engineering department. We using the experience and knowledge acquired during the 15 years we have taught transport phenomena at the graduate level. We have taught transport phenomena at the graduate level by discussing the simultaneous transfer of mass, energy and momentum.

Because we do not have pedagogical training, much of what we do is based on the following observations:

1) Students have significantly decreased their dedication to study, especially when the proposed activities are to be completed at home.

2) They prefer a summary of everything we analyze in the classroom instead of long and monotonous lectures, especially ones given in PowerPoint.

3) They prefer to follow lectures with a summary on the blackboard and/or simultaneously with notes in Word, PDF or PowerPoint on individual computers or in pairs.

4) They prefer to participate in lectures and perform activities that use the knowledge that they already have and/or have acquired during that day right away.

5) We can "force" students to "study in the classroom", "participate in lectures" and "perform all activities in the classroom".

We teach the heat transfer course in the fifth semester of a five-year chemical engineering degree program. The students enrolled in Heat Transfer have already attended, among others, three courses on mathematics for engineering, Momentum Transfer, four physics courses, two thermodynamics courses and Computational Methods for Chemical Engineering.

In the past three years, we have replaced the traditional exam with four or five activities per month, which the students complete in the classroom. These are completed in pairs using Excel spreadsheets and developing and adapting simulation programs written in Fortran. In addition, we begin the course by discussing a problem in transient heat transfer from time zero to infinity. We chose to begin the course with microscopic transient balances and then to analyze macroscopic balances. We discuss analytic solutions and the use the method of lines to solve transient problems or in steady-state. Using the numerical method of lines, starting with the transient solution, we make the time a very large value in the computer program and we obtain the solution of the steady-state.

We tested this methodology with the Heat Transfer students and followed its impact on their motivation and learning in a computer lab used as classroom. We developed a questionnaire to verify the level of satisfaction of the students in the course. It is a synthesis of the method we use, which is based on microscopic 
transient balances or steady states, which are discussed during the first three months of each semester. We do not include questions on the choice to begin the course with microscopic balances and then continue with macroscopic balances or vice versa.

The paper is structured as follows:

- In Section 2, we discuss the evolution of the heat transfer course over the last 17 years that we have taught this at undergraduate level. It has resulted in the syllabus we currently use.

- In Section 3, we discuss the current method used in the Heat Transfer course.

- In Section 4, we discuss some examples presented in class and analyze the students' answers to the questionnaire in semesters 2015.1 and 2016.1. We solve two problems to illustrate the methodology employed in class. Finally we discuss the students' responses to the questionnaire.

- In Section 5, we present the conclusions of the present study.

\section{Evolution of the Syllabus of the Heat Transfer Course}

In this section, we discuss the evolution of the heat transfer course over the last 17 years in which we taught it at the undergraduate level. The result is in the syllabus we currently use.

\subsection{Old Syllabus of the Heat Transfer Course}

For 15 years, we have given chemical engineering lectures on transport phenomena at the graduate level and on heat transfer at the undergraduate level with the following approach:

1) Start with transient or steady-state macroscopic balances;

2) Continue with microscopic transient balances and conclude with microscopic steady-state balances; and

3) Start with macroscopic balances; we believed that this facilitated learning because in general, macroscopic problems are easier to solve than microscopic problems, and less information is required to obtain such solutions.

In Table 1, we present a summary of the old syllabus of the heat transfer course.

\subsection{New Syllabus for the Heat Transfer Course}

For a long time, we have been thinking about starting the heat transfer course with transient processes, and we currently teach it with the following approach:

1) We begin with microscopic transient balances.

2) We continue with microscopic steady-state balances.

3) We conclude with macroscopic transient or steady-state balances.

Table 1. Old heat transfer syllabus.

Part 1. Macroscopic transient or steady-state transport balances.

Part 2. Microscopic transient transport balances.

Part 3. Microscopic steady-state transport balances. 
4) We begin with microscopic balances because we believe that with this method, the students can develop a solid knowledge of transport phenomena, in comparison with starting with macroscopic balances. In addition, we can solve macroscopic problems by integrating basic microscopic equations etc.

5) We begin with a simple transient problem to reduce the possible "initial shock" that we could cause the students to experience. After the students become accustomed to the methodology, it is possible that it would "seem natural" to them to begin with an analysis of a transient problem.

6) We easily understand any steady-state process after understanding it as a global process, from time zero until it reaches a steady state.

7) The initial phase of a process is generally a transient problem, as are some accidents, unexpected actions or operating errors in industry.

8) The integration of dynamic or transient simulations into the chemical engineering curriculum has aroused considerable interest due to the increasing use of simulators for designing processes, control, training and operational support in industry (Komulainen, Enemark-Rasmussen, Sin, Fletcher, \& Cameron, 2012: p. e153).

In Table 2, we present a summary of the current heat transfer syllabus.

\section{Current Methodology Used in Heat Transfer Course}

We teach the heat transfer course with the following methodology:

1) We use a classroom with computers for all students, who work in pairs.

2) We make notes in Word, PDF or PowerPoint available to students; these include guides in the form of problems for each section of the course, a summary of the theory and partial or complete solutions to most of the problems.

3) We conduct the lectures in a sequence that approximately follows the guiding problems.

4) In general, we teach part of the theory and immediately, or concomitantly, solve a problem on the subject under discussion.

5) Usually, in the next step, the groups of students perform calculations, solve problems or discuss basics. They use Excel spreadsheets, develop or adapt computer programs, solve problems analytically etc.

6) The students perform some activities individually to comply with the regulations of the undergraduate program in chemical engineering; for example, discussing calculations previously made or analyzing some basics.

7) We conduct the lectures as expositions using the blackboard, but encourage the students to participate in the development of the topics. When necessary, we use multimedia to present some parts of the course, as well as figures, diagrams or tables.

Table 2. Current heat transfer syllabus.

Part 1. Microscopic transient transport balances.

Part 2. Microscopic steady-state transport balances.

Part 3. Macroscopic transient or steady-state transport balances. 
We highlight the following examples of items that we analyze in the classroom to "catch students' attention" as part of the teaching, feedback and learning process:

1) At the beginning of the lecture, "we perform some kind of staging in the classroom", to which we bring simple resources: cylindrical containers, tubes, small tubes, plates, liquids such as water etc. We perform that "staging" so that students can easily "feel" the course without the need for $100 \%$ abstraction and/or without the need for a traditional transport phenomena laboratory.

2) During the "staging", we move water in free fall, in tubes, in small tubes, over surfaces or inside containers to discuss convection; in addition, we mention traditional examples in books.

3) In another "staged" situation, we mount a concentric tube heat exchanger in the classroom; using two transparent tubes and some accessories, we adjust it to simulate a real exchanger. We clarify that the inner tube is generally built with a suitable material based on the type of fluid, but on many occasions, the material is a good conductor.

\section{Results and Discussion}

In this section, we discuss some examples presented in the classroom and analyze the results of the questionnaire completed by students in the semesters 2015.1 and 2016.1.

\subsection{Results and Discussion of the Intuitive Analysis of Transient Heat Transfer in a Slab}

We highlight some aspects of the problem of this section:

1) We discuss the current problem of giving students a first experience with transient phenomena that uses all the intuitive knowledge that they bring with them.

2) In the development of the problem, we discuss in simple terms the concept of heat conduction in a slab and the basis of conductive heat flux.

3 ) In the figures presented, we show and analyze both the temperature $(T)$ at each point $(x)$ in time $(t)$ and the flux's value and direction $\left(q_{x}\right)$, i.e., whether the flux is positive, negative or zero.

\section{Example (1) - Intuitive Analysis of Transient Heat Transfer in a Slab}

Analyze the following heat transfer problem in a slab that is initially at a constant temperature $\left(T_{0}\right)$ and is subjected to another constant temperature $\left(T_{1}\right)$ on both surfaces at the points $x=-L$ and $x=+L$ when the process begins. The slab, which has length $(2 \mathrm{~L})$ and coordinates in the interval $-L \leq x \leq+L$, has constant density $\rho\left(\mathrm{kg} / \mathrm{m}^{3}\right)$, constant thermal conductivity $k\left[\mathrm{~W} /\left(\mathrm{m} \cdot{ }^{\circ} \mathrm{C}\right)\right]$ and constant specific heat $C p\left[\mathrm{~J} /\left(\mathrm{kg} \cdot{ }^{\circ} \mathrm{C}\right)\right]$. The initial condition at $t=0 \mathrm{~s}$ and the boundary conditions are presented below for $T_{0}>T_{1}$ (Bird, Stewart, \& Lighfoot, 2002, 2014; Carslaw \& Jaeger, 1980; Crank, 1976; Luikov, 1968):

$$
T(x, t=0 \mathrm{~s})=T_{0}
$$




$$
\begin{aligned}
& T=T_{1} x=-L t \geq 0 \mathrm{~s} \\
& T=T_{1} x=+L t \geq 0 \mathrm{~s}
\end{aligned}
$$

Physically, the process occurs in the following sequence:

1) We present the situation of the slab before the process begins at $t<0^{+} \mathrm{s}$ in Figure 1.

2) At time $t=0^{+} \mathrm{s}$, the slab is subjected to a temperature $T_{1}<T_{0}$ at its ends, $x=$ $-L$ and $x=+L$.

In Figure 2, we present the slab at the beginning of the cooling process, i.e., at $t=0^{+} \mathrm{s}$. At time $t=0^{+} \mathrm{s}$, the transient state begins with $T=T_{1}$ at $x=-L$ and $x=$ $+L$; at all other points, the slab is at the initial temperature $\left(T_{0}\right)$. Instantaneously, energy flow from the two edges of the slab, $x=-L$ and $x=+L$. When $t>0$ s, the slab is in a transient state and has a temperature profile, $T(x, t)$, that is a function of time $(t)$ and position $(x)$. There is a diffusive heat flux, $q_{x}\left(\mathrm{~W} / \mathrm{m}^{2}\right)=-k \partial T / \partial x$, of the type $q_{x}(x, t)$. In other words, there is a flux "profile", $q_{x}(x, t)$, that is a function of time $(t)$ and position $(x)$.

3) Continuation of the transient state with a maximum at the center of the slab, $x=0 \mathrm{~m}$.

Shown in Figure 3 is the maximum at the center of the slab, $x=0 \mathrm{~m}$; each

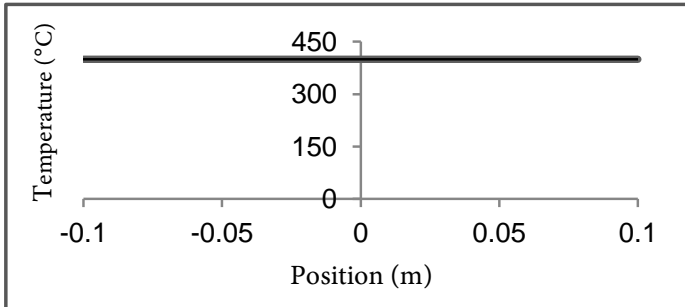

Figure 1. Slab before the process begins at $t<0^{+} \mathrm{s}$.

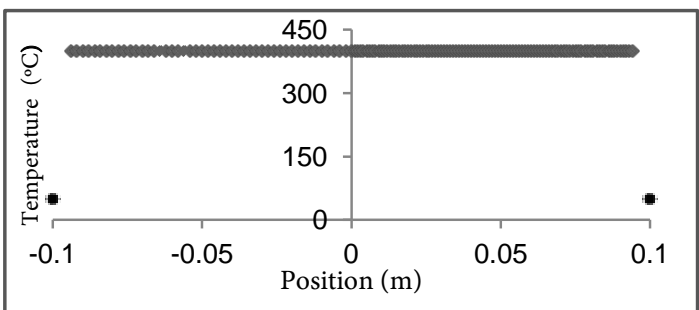

Figure 2. Slab at the beginning of the cooling process at $t=0^{+} \mathrm{s}$.

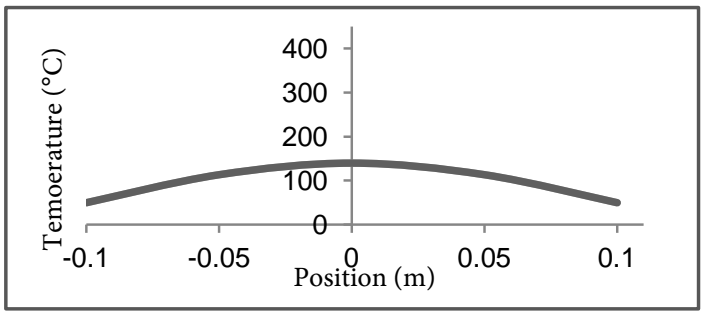

Figure 3. Slab during the transient cooling process at $t=600 \mathrm{~s}$. 
maximum has a different temperature $(T)$ at each time $(t)$. In other words, at point $x=0 \mathrm{~m}$, which has the maximum temperature, there is no heat flux; the temperature is $T_{\max }(x=0 \mathrm{~m}, t)$.

4) For a very long time, i.e., as time tends to infinity $t \rightarrow \infty$, the temperature throughout the slab remains constant $\left(T_{1}\right)$.

In Figure 4, we present the situation in the slab when it reaches a steady state, i.e., after the cooling process. The temperature of the slab is constant as time $t \rightarrow \infty$ because the $(k)$ is constant and there is no power generation $G_{e}\left(\mathrm{~W} / \mathrm{m}^{3}\right)$ due to, for example, electrical resistance or chemical or nuclear reactions inside the slab that may influence the temperature profile. The temperature is a linear function of the type $T=f(x)=a+b x$, however because at $x=-L$ and $x=+L$ the temperature is $\left(T_{1}\right)$, it will be constant all over the slab, i.e., $T=T_{1}$. In other words, the slab will reach a steady state as $t \rightarrow \infty$ in which $T=T_{1}$.

After the process reaches the steady state, the slab temperature $(T)$ does not change over time $(t)$; it is a constant, $T=T_{1}$, at all positions. In this situation, the conductive flux is zero, i.e., $q_{x}=-k \partial T / \partial X=0$. In other words, the flux is constant and equal to zero, $q_{x}=0$, because $(k)$ is constant and the temperature gradient is zero $(\partial T / \partial x=0)$ because the temperature is constant $\left(T=T_{1}\right)$ across the slab. Evidently, the heat flux can be calculated as $q_{x}(x, t)=-k \partial T / \partial X$ in both the transient and the steady state but is zero after the steady state is reached.

\subsection{Results and Discussion of Transient Heat Transfer in a Slab}

We highlight some aspects of the problem:

1) The following problem is similar to the previous problem; however we include data and perform calculations.

2) In a previous lecture, we presented the basics of using Excel, and the students performed activities such as obtaining the first root or multiple roots of an equation.

3) In another lecture, we analyzed the microscopic transport balances for a pure fluid, i.e., the continuity, momentum and energy equations.

4) At another convenient time, we presented a summary of the numerical method of lines for solving problems.

Example (2)-Transient Heat Transfer in a Slab

Solve the heat transfer problem for a solid slab of width $2 L$ using the microscopic

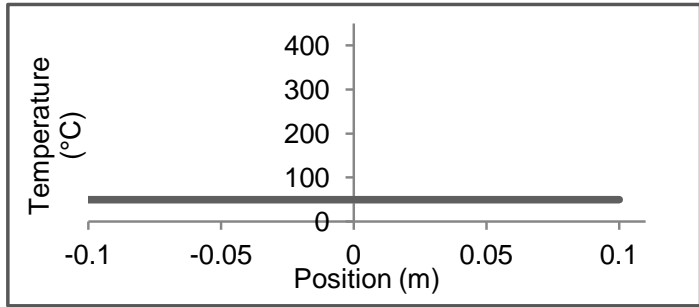

Figure 4. Slab after reaching the steady state during cooling as $t \rightarrow \infty$. 
continuity equation with constant properties $(k, \rho$ and $C p)$ and unsteady heat conduction equation in $(x)$ to obtain the following (Bird, Stewart, \& Lighfoot, 2002, 2014; Carslaw \& Jaeger, 1980; Crank, 1976; Luikov, 1968):

1) The transient temperature profile $T=f(x, t)$, assuming that the slab was at temperature $\left(T_{0}\right)$ for $t<0^{+} \mathrm{s}$ and that at time $t>0 \mathrm{~s}$, it was subjected to temperature $\left(T_{1}\right)$ at $x=-L$ and $x=+L$.

Assuming that $(\rho)$ is constant and that the slab is stationary, we do not obtain important information from the continuity equation for the slab. The unsteady state equation of heat conduction in $(x)$, assuming that the thermal diffusivity is a constant, i.e., $\alpha=k /(\rho C p)$, becomes:

$$
\frac{\partial T}{\partial t}=\alpha \frac{\partial^{2} T}{\partial x^{2}}
$$

We obtain the transient profile $T(x, t)$ using, for example, separation of variables or Laplace transform, with the initial condition and the two boundary conditions mentioned above [Bird, Stewart, \& Lighfoot, 2002: pp. 376 to 378, example (12.1-2); Crank, Equation (4.17), 1976: p. 47] for $-L \leq x \leq L$ as follows:

$$
\frac{T-T_{1}}{T_{0}-T_{1}}=\sum_{n=1}^{\infty} \frac{2(-1)^{n+1}}{(2 n-1) \pi / 2} \cos \left[(2 n-1) \frac{\pi}{2} \frac{x}{L}\right] \exp \left\{-\left[(2 n-1) \frac{\pi}{2}\right]^{2} \frac{k t}{\rho C p L^{2}}\right\}
$$

The terms $\mu_{n}=(2 n-1) \pi / 2$ are called eigenvalues, and when we use them in the infinite series in Equation (5), we retrieve the initial condition and the boundary conditions of the problem. These results exhibit some of the important uses of the eigenvalues that we study in mathematics courses for engineering but that sometimes are not easy to understand.

If we move $\alpha=k /(\rho C p)$ to the right hand side of Equation (1) and multiply the numerator and denominator by $\left(L^{2}\right)$, we obtain $\partial T / \partial F O=\partial^{2} T / \partial(x / L)^{2}$, and thus, the Fourier number, $F o=\alpha t / L^{2}$, comes naturally from the heat conduction equation. $F o=\alpha t / L^{2}$ is important to the convergence of the series in Equation (5). In general, if $F o>0.5$, we can use only the first term in the series in Equation (5), or of similar solutions for common geometries, with a relative percent deviation $(|\operatorname{RPD}|)$ in the calculation of $(\mathrm{T})$, i.e., almost always $<1 \%$, instead of the infinitely many terms in Equation (5).

To obtain the solution of Equation (4), which is given by Equation (5), we start with Equation (4), which is a valid differential equation for a point, and we integrate it to obtain Equation (5), which is valid for all points in $-L \leq x \leq L$. In other words, we start from a microscopic equation to achieve a macroscopic result.

2) The temperature at any point $(x)$ on the slab as $t \rightarrow \infty$ is equal to $\left(T_{1}\right)$.

For infinite time (as $t \rightarrow \infty$ ), we calculate the exponential term of Equation (5) as $\exp (-\infty) \rightarrow 0$, the term $\cos \left(A_{n} x\right)=$ finite with $A_{n}=(2 n-1) \pi /(2 L)$ for $-L \leq x \leq L$, and from Equation (2), we find that $T=T_{1}$ as follows:

$$
\frac{T-T_{1}}{T_{0}-T_{1}}=\sum_{n=1}^{\infty} \frac{2(-1)^{n+1}}{(2 n-1) \pi / 2} \cos \left[(2 n-1) \frac{\pi}{2} \frac{x}{L}\right] \exp (-\infty)=0 \Rightarrow T=T_{1}
$$

This result is important because from it we obtain the temperature at infinite 
time, i.e., the steady-state temperature, which in this particular situation is constant and equal to $\left(T_{1}\right)$.

3) The temperature at $x=-L$ or $x=+L$ both for finite time $(t)$ and for $t \rightarrow \infty$.

Knowing that $\cos [(2 n-1) \pi / 2]=0$ allows us to determine that the temperatures $T(x= \pm L, t=t)=T_{1}$ both at any finite time $(t)$ and as $t \rightarrow \infty$ using Equation (5) as follows:

$$
\frac{T-T_{1}}{T_{0}-T_{1}}=\sum_{n=1}^{\infty} \frac{2(-1)^{n+1}}{(2 n-1) \pi / 2}(0) \exp \left\{-\left[(2 n-1) \frac{\pi}{2}\right]^{2} \frac{k t}{\rho C p L^{2}}\right\}=0 \Rightarrow T=T_{1}
$$

With the result presented in Equation (7), $T=T_{1}$, we retrieve the boundary conditions at $x=-L$ and $x=+L$. In addition, this result is valid for $t \rightarrow \infty$, which is when the slab reaches a steady state.

4) The temperature at time $t=0 \mathrm{~s}$ as equal to $\left(T_{0}\right)$.

We obtain this temperature using the following procedure. At $t=0 \mathrm{~s}$ and $x=0$ $\mathrm{m}, \cos (0)=1, \exp (-0)=1$ and from a table, such as the one in Spiegel, Lipschutz, \& Liu (2009: p. 135), we find that the sum of the series

$\sum(-1)^{n} /(2 n-1)=1-1 / 3+1 / 5-1 / 7+\cdots=\pi / 4$. By substituting this value into the infinite series in Equation (5), we obtain $T=T_{0}$ as follows:

$$
\frac{T-T_{1}}{T_{0}-T_{1}}=\sum_{n=1}^{\infty} \frac{2(-1)^{n+1} \cos (0)}{(2 n-1) \pi / 2}=\frac{4}{\pi}\left(\frac{1}{1}-\frac{1}{3}+\frac{1}{5}-\frac{1}{7}+\cdots\right)=\frac{4}{\pi} \frac{\pi}{4}=1 \Rightarrow T=T_{0}
$$

The result obtained in Equation (8) justifies the infinite number of eigenvalues $\left(\mu_{n}\right)$ needed to retrieve the value $\left(T_{0}\right)$ which is the initial condition. If we had used any value in $-L \leq x \leq L$ other than $x=0 \mathrm{~m}$, the result would be the same, but we would have to consider the terms with $\cos \left(A_{n} x\right)$.

5) The steady-state temperature profile $T=f(x)$.

We obtain the steady-state temperature profile, $T(x)$, from Equation (5) by assuming $t \rightarrow \infty, \cos (A x)=$ finite, and $A=(2 n-1) \pi /(2 L)$ for $-L \leq x \leq L$; the result, $T=T_{1}$ is obtained as follows:

$$
\frac{T-T_{1}}{T_{0}-T_{1}}=\sum_{n=1}^{\infty} \frac{2(-1)^{n+1}}{(2 n-1) \pi / 2} \cos \left[(2 n-1) \frac{\pi}{2} \frac{x}{L}\right] \exp (-\infty)=0 \Rightarrow T=T_{1}
$$

We can obtain the steady-state profile another way. In other words, by solving Equation (1) with the accumulation term equal to zero, i.e., $\partial T / \partial t=0$, and then applying the boundary conditions $T=T_{1}$ at $x=-L$ and $x=L$, integrating twice and calculating the integration constants $\left(C_{1}\right.$ and $\left.C_{2}\right)$ yields, at infinite time, a constant temperature profile, $T=T_{1}$ :

$$
0=\frac{\partial}{\partial x}\left(k \frac{\partial T}{\partial x}\right) \Rightarrow k \frac{\mathrm{d} T}{\mathrm{~d} x}=C_{1} \Rightarrow T=\frac{C_{1} x}{k}+C_{2} \Rightarrow C_{2}=T_{1} \Rightarrow C_{1}=0 \Rightarrow T=T_{1}(10)
$$

6) The heat flux, $q_{x}=-k \partial T / \partial x$, in transient and steady state.

By deriving the temperature in unsteady state or the steady state using Equation (5) and Equation (6) or Equation (10), respectively, the derivative $\mathrm{d}\left(\cos \left(A_{n} x\right)\right) / \mathrm{d} x=-A_{n} \sin \left(A_{n} x\right)$ and the parameter $A_{n}=(2 n-1) \pi /(2 L)$, we obtain, respectively 


$$
\begin{gathered}
q_{x}=\frac{2 k\left(T_{0}-T_{1}\right)}{L} \sum_{n=1}^{\infty}(-1)^{n+1} \sin \left[(2 n-1) \frac{\pi}{2} \frac{x}{L}\right] \exp \left\{-\left[(2 n-1) \frac{\pi}{2}\right]^{2} \frac{\alpha t}{L^{2}}\right\} \\
q_{x}=-k \frac{\partial T}{\partial x}=-k \frac{\partial\left(T_{1}\right)}{\partial x}=0
\end{gathered}
$$

Clearly, in Equation (12), we have no flux as $t \rightarrow \infty$ because the temperature in the slab is a constant $\left(T_{1}\right)$ and the flux is zero, i.e., $q_{x}=0 \mathrm{~W} / \mathrm{m}^{2}$. However, according to Equation (11), the flux is of the type $q_{x}(x, t)$, which changes with position $(x)$ and time $(t)$, however can reach zero as $t \rightarrow \infty$.

7) The temperature at any point on the slab, $T(x, t)$, using the first term of Equation (5).

We calculate the temperature in the slab of width $2 L=0.2 \mathrm{~m}$ using the first term of Equation (5) at the points $x=-L=-0.1 \mathrm{~m}, x=-0.05 \mathrm{~m}, x=0 \mathrm{~m}$, $x=+0.05 \mathrm{~m}$ and $x=+L=0.1 \mathrm{~m}$ for $t=600 \mathrm{~s}, T_{0}=400^{\circ} \mathrm{C}, T_{1}=50^{\circ} \mathrm{C}, k=$ $37.7 \mathrm{~W} /\left(\mathrm{m} \cdot{ }^{\circ} \mathrm{C}\right), \rho=7.822 \mathrm{~kg} / \mathrm{m}^{3}, C p=444 \mathrm{~J} /\left(\mathrm{kg} \cdot{ }^{\circ} \mathrm{C}\right)$ and $\alpha=k /(\rho C p)=1.0855 .10^{-5} \mathrm{~m}^{2} / \mathrm{s}$. We obtain the results below using $F o=\alpha t / L^{2}=0.651, \cos ( \pm \pi / 2)=0$ and $\cos (0)=1$; we note that the temperature $(T)$ is symmetric around $x=0 \mathrm{~m}$, which is the reference point.

$$
\begin{aligned}
\frac{T-50^{\circ} \mathrm{C}}{(400-50)^{\circ} \mathrm{C}} & =\frac{2(-1)^{1+1}}{\pi / 2} \cos \left[\frac{\pi}{2} \frac{(-0.10 \mathrm{~m})}{(0.10 \mathrm{~m})}\right] \exp \left[-\left(\frac{\pi}{2}\right)^{2} 0.651\right]=0 \Rightarrow T=T_{1} \\
& =50.0^{\circ} \mathrm{C} \\
\frac{T-50^{\circ} \mathrm{C}}{(400-50)^{\circ} \mathrm{C}} & =\frac{2(-1)^{1+1}}{\pi / 2} \cos \left[\frac{\pi}{2} \frac{(-0.05 \mathrm{~m})}{(0.10 \mathrm{~m})}\right] \exp \left[-\left(\frac{\pi}{2}\right)^{2} 0.651\right]=0.180 \Rightarrow T \\
& =113.17^{\circ} \mathrm{C} \\
\frac{T-50^{\circ} \mathrm{C}}{(400-50)^{\circ} \mathrm{C}} & =\frac{2(-1)^{1+1}}{\pi / 2} \cos \left[\frac{\pi}{2} \frac{(0 \mathrm{~m})}{(0.10 \mathrm{~m})}\right] \exp \left[-\left(\frac{\pi}{2}\right)^{2} 0.651\right]=0.255 \Rightarrow T \\
& =139.34^{\circ} \mathrm{C} \\
\frac{T-50^{\circ} \mathrm{C}}{(400-50)^{\circ} \mathrm{C}} & =\frac{2(-1)^{1+1}}{\pi / 2} \cos \left[\frac{\pi}{2} \frac{(+0.05 \mathrm{~m})}{(0.10 \mathrm{~m})}\right] \exp \left[-\left(\frac{\pi}{2}\right)^{2} 0.651\right]=0.18 \Rightarrow T \\
& =113.17^{\circ} \mathrm{C} \\
\frac{T-50^{\circ} \mathrm{C}}{(400-50)^{\circ} \mathrm{C}} & \left.=\frac{2(-1)^{1+1}}{\pi / 2} \cos \left[\frac{\pi}{2} \frac{(+0.10 \mathrm{~m})}{(0.10 \mathrm{~m})}\right] \exp \left[-\left(\frac{\pi}{2}\right)^{2} 0.651\right]=0 \Rightarrow T=T_{1}(17)\right] \\
& =50.0^{\circ} \mathrm{C}
\end{aligned}
$$

8) The temperature at any point on the slab, $T(x, t)$, using the first two terms of Equation (2).

We obtain the results below using the first two terms of Equation (5). We detail the calculation for $x=-0.1 \mathrm{~m}, t=600 \mathrm{~s}$ and $F o=0.651$ and present only the results for the other points.

$$
\begin{aligned}
T= & 50^{\circ} \mathrm{C}+\left(400^{\circ} \mathrm{C}-50^{\circ} \mathrm{C}\right)\left\{\frac{2(-1)^{1+1}}{\pi / 2} \cos \left[\frac{\pi}{2} \frac{(-0.10 \mathrm{~m})}{(0.10 \mathrm{~m})}\right] \exp \left[-\left(\frac{\pi}{2}\right)^{2} 0.651\right]\right. \\
& \left.+\frac{2(-1)^{2+1}}{3 \pi / 2} \cos \left[\frac{3 \pi}{2}(-1)\right] \exp \left[-\left(\frac{3 \pi}{2}\right)^{2} 0.651\right]\right\}=50^{\circ} \mathrm{C}
\end{aligned}
$$




$$
\begin{gathered}
T(x=-0.05 \mathrm{~m}, t=600 \mathrm{~s})=113.17^{\circ} \mathrm{C} \\
T(x=0 \mathrm{~m}, t=600 \mathrm{~s})=139.34^{\circ} \mathrm{C} \\
T(x=+0.05 \mathrm{~m}, t=600 \mathrm{~s})=113.17^{\circ} \mathrm{C} \\
T(x=+0.1 \mathrm{~m}, t=600 \mathrm{~s})=T_{1}=50.00^{\circ} \mathrm{C}
\end{gathered}
$$

These results are equal to those calculated using the first term of Equation (5) to two decimal places. This is because $F o=\alpha t / L^{2}>0.5$, which facilitates the convergence of Equation (5). For $F o=0.651$, it is sufficient to use only the first term of Equation (5).

9) The flux at any point on the slab, $q_{x}(x, t)$, using the first term of Equation (11).

We obtain the results presented below for $x=-0.1 \mathrm{~m}, x=-0.05 \mathrm{~m}, x=0 \mathrm{~m}$, $x=+0.05 \mathrm{~m}$ and $x=0.1 \mathrm{~m}$, respectively, for $F o=0.651, \sin ( \pm \pi / 2)= \pm 1$ and $\sin (0)=0$. The flux $q_{x}=0 \mathrm{~W} / \mathrm{m}^{2}$ at $x=0 \mathrm{~m}$, and heat is lost from both surfaces of the slab.

$$
\begin{aligned}
& q_{x}=\frac{2\left(37.7 \frac{\mathrm{W}}{\mathrm{m}^{\circ} \mathrm{C}}\right)(400-50)^{\circ} \mathrm{C}}{0.1 \mathrm{~m}}(-1)^{1+1} \sin \left[\frac{\pi}{2} \frac{(-0.1 \mathrm{~m})}{(0.1 \mathrm{~m})}\right] \exp \left[-\left(\frac{\pi}{2}\right)^{2} 0.651\right] \\
& =-52905.76 \mathrm{~W} / \mathrm{m}^{2} \\
& q_{x}=\frac{2\left(37.7 \frac{\mathrm{W}}{\mathrm{m}^{\circ} \mathrm{C}}\right)(400-50)^{\circ} \mathrm{C}}{0.1 \mathrm{~m}}(-1)^{1+1} \sin \left[\frac{\pi}{2} \frac{(-0.05 \mathrm{~m})}{(0.1 \mathrm{~m})}\right] \exp \left[-\left(\frac{\pi}{2}\right)^{2} 0.651\right](2 \\
& =-37410.02 \mathrm{~W} / \mathrm{m}^{2} \\
& q_{x}=\frac{2\left(37.7 \frac{\mathrm{W}}{\mathrm{m}^{\circ} \mathrm{C}}\right)(400-50)^{\circ} \mathrm{C}}{0.1 \mathrm{~m}}(-1)^{1+1} \sin \left[\frac{\pi}{2} \frac{(0 \mathrm{~m})}{(0.1 \mathrm{~m})}\right] \exp \left[-\left(\frac{\pi}{2}\right)^{2} 0.651\right] \\
& =0 \mathrm{~W} / \mathrm{m}^{2} \\
& q_{x}=\frac{2\left(37.7 \frac{\mathrm{W}}{\mathrm{m}^{\circ} \mathrm{C}}\right)(400-50)^{\circ} \mathrm{C}}{0.1 \mathrm{~m}}(-1)^{1+1} \sin \left[\frac{\pi}{2} \frac{(+0.05 \mathrm{~m})}{(0.1 \mathrm{~m})}\right] \exp \left[-\left(\frac{\pi}{2}\right)^{2} 0.651\right] \text { (26) } \\
& =+37410.02 \mathrm{~W} / \mathrm{m}^{2} \\
& q_{x}=\frac{2\left(37.7 \frac{\mathrm{W}}{\mathrm{m}^{\circ} \mathrm{C}}\right)(400-50)^{\circ} \mathrm{C}}{0.1 \mathrm{~m}}(-1)^{1+1} \sin \left[\frac{\pi}{2} \frac{(+0.1 \mathrm{~m})}{(0.1 \mathrm{~m})}\right] \exp \left[-\left(\frac{\pi}{2}\right)^{2} 0.651\right] \\
& =+52905.76 \mathrm{~W} / \mathrm{m}^{2}
\end{aligned}
$$

The flux in the slab is negative for $x=-0.1 \mathrm{~m}$ and positive for $x=+0.1 \mathrm{~m}$. It is considered positive on the positive side of the $x$-axis, i.e., from $x=0 \mathrm{~m}$ to $x=$ $+0.1 \mathrm{~m}$. Using this sign convention, heat is lost from both surfaces of the slab until we reach the steady state, when the flux becomes zero,

$q_{x}(x, t \rightarrow \infty)=0 \mathrm{~W} / \mathrm{m}^{2}$.

10) The flux at any point on the slab, $q_{x}(x, t)$, using the first two terms of Equation (11). 
We obtain the flux using the first two terms of the series in Equation (11). The results are listed below; we highlight the calculations for $x=-0.1 \mathrm{~m}, t=600 \mathrm{~s}$ and $F o=0.651$.

$$
\begin{gathered}
q_{x}=\frac{2\left(37.7 \frac{\mathrm{W}}{\mathrm{m}^{\circ} \mathrm{C}}\right)(400-50)^{\circ} \mathrm{C}}{0.1 \mathrm{~m}}\left\{(-1)^{1+1} \sin \left[\frac{\pi}{2} \frac{(-0.1 \mathrm{~m})}{(0.1 \mathrm{~m})}\right] \exp \left[-\left(\frac{\pi}{2}\right)^{2} 0.651\right]\right. \\
\left.+(-1)^{2+1} \sin \left[\frac{3 \pi}{2}(-1)\right] \exp \left[-\left(\frac{3 \pi}{2}\right)^{2} 0.651\right]\right\}=-52905.90 \frac{\mathrm{W}}{\mathrm{m}^{2}} \\
q_{x}(x=-0.05 \mathrm{~m}, t=600 \mathrm{~s})=-37409.92 \mathrm{~W} / \mathrm{m}^{2} \\
q_{x}(x=0 \mathrm{~m}, t=600 \mathrm{~s})=0 \mathrm{~W} / \mathrm{m}^{2} \\
q_{x}(x=-0.1 \mathrm{~m}, t=600 \mathrm{~s})=37409.92 \mathrm{~W} / \mathrm{m}^{2} \\
q_{x}(x=+0.1 \mathrm{~m}, t=600 \mathrm{~s})=+52905.90 \mathrm{~W} / \mathrm{m}^{2}
\end{gathered}
$$

We calculate that the deviations of the fluxs of this item in relation to the previous item as satisfying $|\mathrm{RPD}|<1 \%$. Generally, $|\mathrm{RPD}|<5 \%$ is sufficient for engineering calculations. In these calculations, we do not consider the experimental error in the properties $(k, \rho$ and $C p)$, in dimension $(x)$ etc., which must be considered in detailed calculations.

11) Develop a computer program to calculate the transient temperature profile, $T(x, t)$, and the flux, $q_{x}(x, t)$, at any point $(x)$ and time $(t)$. (You may use a commercial program or an appropriate program obtained from another source).

In Table 3 and Table 4, we present a computer program and a Fortran subroutine, respectively, to calculate the temperature, $T(x, t)$, and the flux, $q_{x}(x, t)$.

In previous lectures, we discussed the use of the method of lines. There are several references in the literature that introduce the method of lines and dig deeper into the subject (Cutlip \& Shacham, 1999; Sadiku \& Obiozor, 2000; Schiesser \& Silebi, 2009; Wouwer, Saucez, \& Vilas, 2014).

Due to the symmetry of the temperature profile, by discretizing Equation (4) using centered finite differences and numbering the nodes of half of the slab's width $(L)$ from $i=1$ to $i=n$, we obtain, for $i=2$ to $(n-1)$

$$
\frac{\mathrm{d} T(i)}{\mathrm{d} t}=\frac{\alpha[T(i-1)-2 T(i)+T(i+1)]}{\Delta x^{2}} 2 \leq i \leq(n-1)
$$

We write the initial condition for all points satisfying $0 \leq x \leq L$, which is already set in the nomenclature of the computer program, as

$$
T(1: n)=T_{0} t=0 \mathrm{~s} \quad 0 \leq x \leq L
$$

We obtain the boundary condition for $x=+L$, i.e., $i=n$ or the right edge, as

$$
T(n)=T_{1} \quad t=0 \mathrm{~s} \quad x=L
$$

We write the boundary condition at $x=0 \mathrm{~m}$, i.e., $i=1$, which, due to the symmetry of the temperature profile, has no flux at that point $\left(q_{x}(i=1)=0 \mathrm{~W} / \mathrm{m}^{2}\right)$. Using the definition of the flux at $x=0 \mathrm{~m},-k \mathrm{~d} T / \mathrm{d} x=0$, 
Table 3. Computer program for calculating temperature and heat flux in a slab.

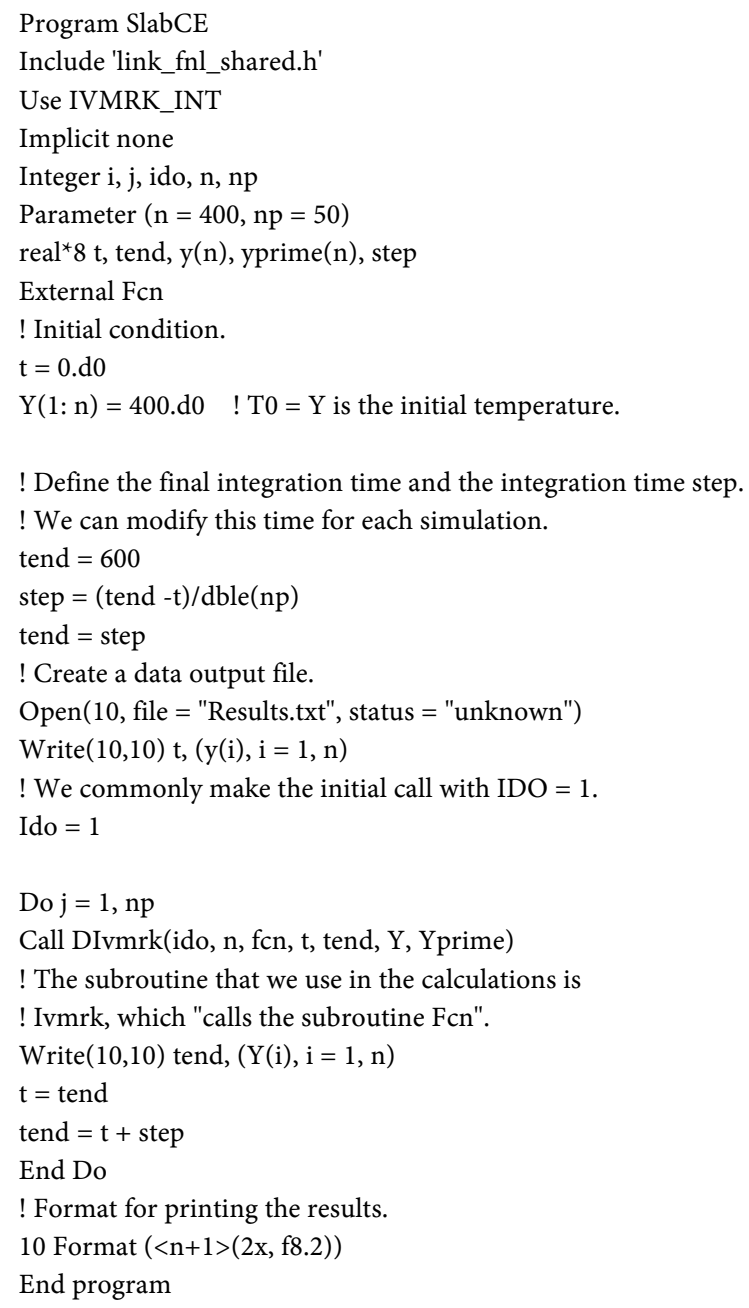

i.e., $-k[T(2)-T(1)] / \Delta x=0$, we obtain

$$
T(1)=T(2) \quad t=0 \mathrm{~s} \quad x=0 \mathrm{~m}
$$

We solve the system of equations, including Equation (33) with the $\partial T / \partial t$ term and Equations (34), (35) and (36) for $0 \leq x \leq L$ due to the symmetry with the computer program.

In the program, we write the temperature $(T)$ as the variable $(Y)$ and the derivative $\partial T / \partial t$ as $Y$ prime $=\mathrm{d} Y / \mathrm{d} t$. We use the method of lines to solve the system of equations and obtain the temperature $T(x, t)$ at all points in $0 \leq x \leq L$ and, due to the symmetry, in $-L \leq x \leq 0$. We execute the computer program for $t=t_{\text {end }}=600 \mathrm{~s}, n=400$ and obtain

$T(1)=138.98^{\circ} \mathrm{C}, T(2)=138.98^{\circ} \mathrm{C}, \cdots, T(n-1)=50.35^{\circ} \mathrm{C}$ and $T(n)=50.00^{\circ} \mathrm{C}$. The temperature at $x=0 \mathrm{~m}$, calculated using the analytical solution, is $T(1)=$ $139.34^{\circ} \mathrm{C}$, which, when compared with the numerical solution, $T(1)=138.98^{\circ} \mathrm{C}$, produces RPD $=-0.3 \%$. For $n=400$ and $\Delta x=L /(n-1)=(0.1 \mathrm{~m}) /(400-1)$, we calculate the flux at $x=+L$, using $T(n-1)=50.35^{\circ} \mathrm{C}, T(n)=50.00^{\circ} \mathrm{C}$ and $k=$ $37.7 \mathrm{~W} /\left(\mathrm{m} \cdot{ }^{\circ} \mathrm{C}\right)$, as $q_{x}=-k[T(n)-T(n-1)] / \Delta x=52648.05 \mathrm{~W} / \mathrm{m}^{2}$. Comparing 
Table 4. Auxiliary subroutine program assistant for the numerical temperature and heat flux calculations.

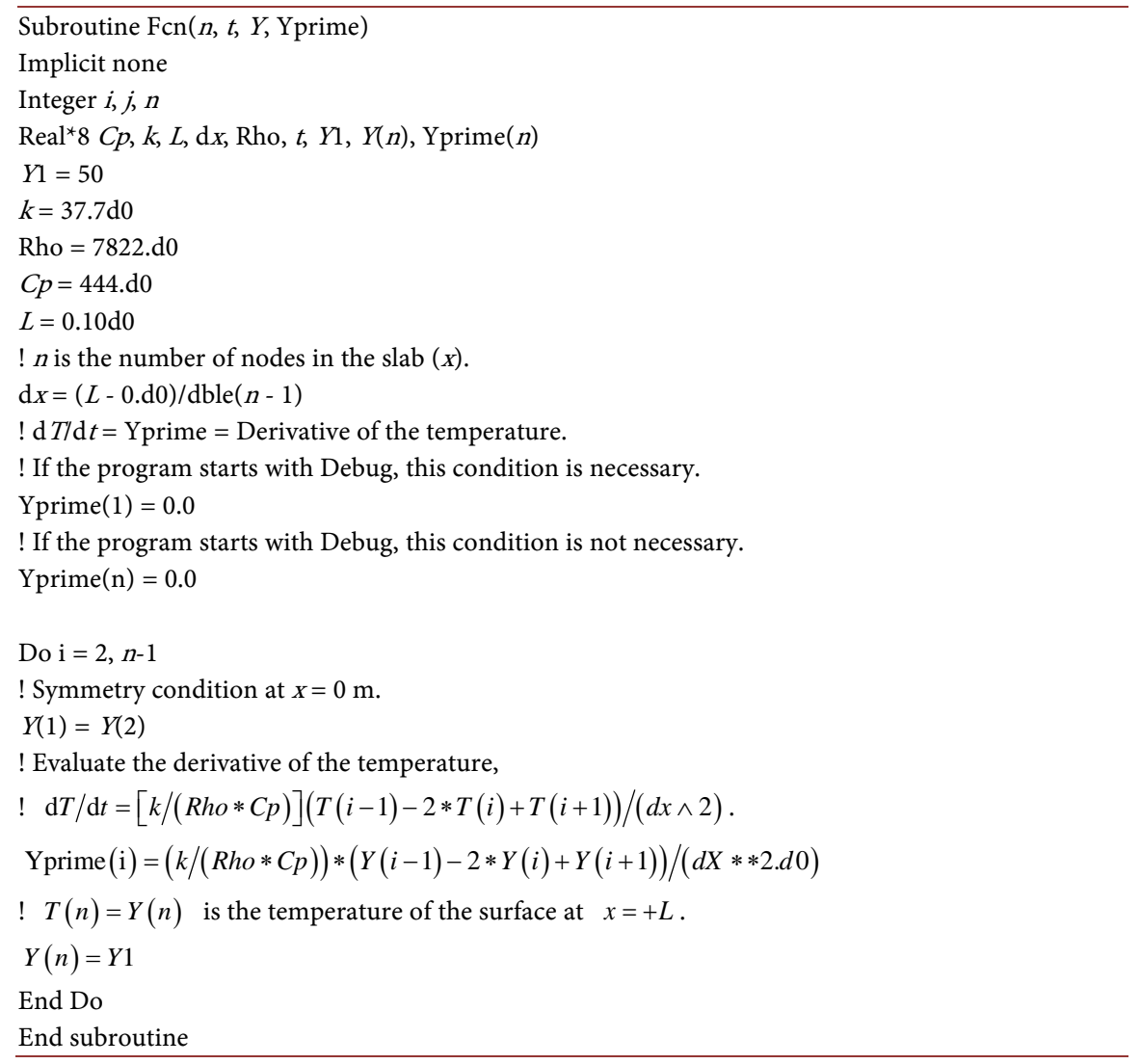

this flux with that of the analytical solution, $q_{x}=52,905.90 \mathrm{~W} / \mathrm{m}^{2}$, we obtain $\mathrm{RPD}=-0.5 \%$. Generally, for engineering calculations, a precision on the order of RPD $=5 \%$ is sufficient.

\subsection{Results and Discussion of the Answers to the Questionnaire Submitted by the Students}

In Table 5 and Table 6, we present the questionnaires that the students responded to in semesters 2015.1 and 2016.1, respectively. In 2015.1, 18 of the 27 students enrolled in Heat Transfer were present for the questionnaire, and 17 responded. In 2016.1, 25 of the 27 students enrolled in the course were present for the questionnaire, and 24 responded. In the following, we present some of the results in the Tables cited above for semesters 2015.1 and 2016.1:

1) In 2015.1 and $2016.1,65 \%$ and $54 \%$, respectively, of the students had little difficulty understanding the theory covered in Heat Transfer.

2) In 2015.1 and $2016.1,59 \%$ and $58 \%$, respectively, had no difficulty calculating microscopic transient balances.

3) In $2015.1,65 \%$ had no difficulty with steady-state calculations, and in 2016.1, 63\% had little difficulty.

4) In $2015.1,76 \%$ preferred to perform all the classroom activities each month, but only $46 \%$ preferred this option in 2016.1 . 
Table 5. Questionnaire on the lectures and activities in heat transfer in 2015.1.

\begin{tabular}{ccc}
\hline Questions & Number of responses per item & Student comments \\
\hline
\end{tabular}

1) Did you have difficulty understanding the theory covered

in Heat Transfer?
( ) No.
4
( ) A little.
( ) Yes, a great deal.

2) Did you have difficulty calculating microscopic transient balances in the activities during that month?

( ) No.

( ) A little.

( ) Yes, a great deal.

3) Did you have difficulty calculating microscopic steady-state balances during that month?

( ) No.

() A little.

( ) Yes, a great deal.

4) Do you prefer the monthly evaluations to be conducted as four or five activities in the classroom, as traditional exams or as another type of evaluation?

( ) I prefer four or five activities in the classroom.

( ) I prefer a traditional exam.

( ) I prefer another type of evaluation. (Describe such an evaluation below).

5) After we discussed the use of Excel in the course, did you have difficulty performing the calculations in the requested activities?

( ) No.

() A little.

( ) Yes, a great deal.

6) Did you have difficulty understanding the basics because we began with transient problems and then, moved to steady-state problems?

( ) No.

( ) A little.

( ) Yes, a great deal.

7) Do you prefer the course to begin with transient problems and then move to steady-state problems or vice versa? Or do you prefer another option?

( ) I prefer that it begin with transient problems.

( ) I prefer that it begin with the steady state.

( ) I prefer that it begin in another way. (Describe how this part of the course should be conducted below).

8) Did you have any difficulty understanding the heat transfer course? Mark the possibilities that apply.

( ) I understand the basics of the course well.

( ) I understand the physical sense of the problems well.

( ) I am able to connect the basics by solving a specific problem. a) Actually, medium difficulty. Even though it was taught in a simple way, the course has its peculiarities and equations that require study.

a) Only for the basics of transient theory.

a) The theoretical basis necessary for the steady-state activities was simple.

a) If it involved following notes or a problem guide, it would be better to perform the activities. If the format of the lectures changed, then a theoretical exam would be interesting.

b) An open seminar containing industrial problems and new technologies in the course.

c) A traditional exam, an activity and homework assignments.

d) $50 \%$ for a traditional exam and $50 \%$ for homework assignments.

e) $50 \%$ to $60 \%$ for activities and the rest for a theoretical exam.

a) I had little difficulty with the Excel tools.

b) I had little difficulty, but I learned some tricks, and now it is easy to make graphs of functions.

a) I do not think I have difficulty with the order but I do with the theoretical basis, which is quite limited.

a) I only understand some of the basics. 


\section{Continued}

( ) I do not have a good understanding of the basics. 5

( ) I do not have a good understanding of the physical

sense of the problems.

( ) I am not able to connect the basics by solving a specific problem.

Table 6. Questionnaire on the lectures and activities in heat transfer in 2016.1.

\begin{tabular}{ccc}
\hline Questions & Number of responses per item & Student comments
\end{tabular}

1) Did you have difficulty understanding the theory covered

in Heat Transfer?

$\begin{array}{lc}\text { ( ) No. } & 1 \\ \text { ( ) A little. } & 13 \\ \text { ( ) Yes, a great deal. } & 10\end{array}$

2) Did you have difficulty calculating the microscopic transient balances activities during that month?

$\begin{array}{lc}\text { ( ) No. } & 14 \\ \text { ( ) A little. } & 10 \\ \text { ( ) Yes, a great deal. } & 0\end{array}$

3) Did you have difficulty calculating the microscopic steady-state microscopic balances during that month?

( ) No.

( ) A little.

( ) Yes, a great deal. 0

4) Do you prefer the monthly evaluations to be conducted as four or five activities in the classroom, as traditional exams or as another type of evaluation?

( ) I prefer four or five activities in the classroom.

( ) I prefer a traditional exam.

( ) I prefer another type of evaluation. (Describe such an evaluation below).

5) After we discussed the use of Excel in the course, did you have difficulty performing the calculations in the requested activities?

( ) No.

( ) A little.

( ) Yes, a great deal.

6

0

6) Did you have difficulty understanding the basics because we began with transient problems and then, moved to steadystate problems?

( ) No.

( ) A little.

( ) Yes, a great deal.

7) Do you prefer the course to begin with transient problems and then move to steady-state problems or vice versa? Or do you prefer another option?

( ) I prefer that it begin with transient problems.

( ) I prefer that it begin with the steady state.

( ) I prefer that it begin in another way. (Describe how this part of the course should be conducted below).
One student did not answer this question.

a) I do not see the importance of these activities of only involving the use of equations. I would like to understand the course and perform activities with awareness of what I do.

b) Three students prefer an exam and activities in the classroom.

c) An exam and a project for us to develop.

f) Three activities and some homework that helps with learning.

e) An exam and an assignment.

f) An exam and activities that help bring together the theory and the calculations.

g) Solving a problem in group after a theoretical class. 


\section{Continued}

8) Did you have any difficulty understanding the heat

transfer course? Mark the possibilities that apply.

( ) I understand the basics of the course well.

( ) I understand the physical sense of the problems 6

well.

( ) I am able to connect the basics by solving a specific $\quad 10$

problem.

( ) I do not understand the basics well. 6

( ) I do not understand the physical sense of the 3

problems well.

( ) I do not connect the basics by solving a specific $\quad 5$

problem.

5) In 2015.1, 53\% had no difficulty understanding the basics because we began with transient problems and then, moved to steady-state problems. In 2016.1, $75 \%$ had little difficulty.

6) In $2015.1,59 \%$ preferred that the course began with transient problems, but in 2016.1, 63\% would have preferred that it begin with steady-state problems.

7) In 2015.1, 47\% understood the basics well, $47 \%$ understood the physical sense of the problems well, and $47 \%$ connected the basics by solving problems. In 2016.1 , only $21 \%$ understood the basics well, $25 \%$ understood the physical sense of the problems well, and $42 \%$ connected the basics by solving problems, which is quite different from 2015.1.

8) In 2015.1, 29\% did not understand the basics well, 18\% did not understand the physical sense of the problems well, and $35 \%$ could not connect the basics by solving a problem. In 2016.1 , only $25 \%$ did not understand the basics well, $13 \%$ did not understand the physical sense of the problems well, and $21 \%$ could not connect the basics by solving a problem.

Next, we present the averages of the students' responses to the questionnaires distributed in semesters 2015.1 and 2016.1 (Table 7). In the calculation, we considered all 41 students that answered the questionnaire. Of the students:

1) $59 \%$ had little difficulty understanding the theory covered in Heat Transfer.

2) $59 \%$ did not have difficulty calculating microscopic transient balances.

3) $46 \%$ did not have difficulty performing steady-state calculations.

4) $59 \%$ preferred the classroom activities to traditional monthly exams.

5) $59 \%$ had little difficulty understanding the basics because we began with transient problems and then moved to steady-state problems.

6) $41 \%$ preferred that the course begin with transient problems, and $51 \%$ preferred to begin with steady-state problems.

7) $32 \%$ understood the basics well, $34 \%$ understood the physical sense of the problems well, and $44 \%$ connected the basics by solving problems.

8) $27 \%$ did not understand the basics well, $15 \%$ did not understand the physical sense of the problems well, and $27 \%$ could not connect the basics by solving a problem.

One of the goals of this study is to discuss the possibility of starting the heat transfer course with transient problems. As we previously showed, in 2015.1, 
Table 7. Summary of the questionnaires on the lectures and activities in heat transfer in 2015.1 and 2016.1.

\begin{tabular}{lll}
\hline Questions & Number of responses per item
\end{tabular}

1) Did you have difficulty understanding the theory covered in Heat Transfer?

$\begin{array}{lc}\text { ( ) No. } & 5 \\ \text { ( ) A little. } & 24 \\ \text { ( ) Yes, a great deal. } & 12\end{array}$

2) Did you have difficulty calculating microscopic transient balances in the activities during that month?

( ) No.

( ) A little.

( ) Yes, a great deal.

3) Did you have difficulty calculating microscopic steady-state balances during that month?

( ) No.

( ) A little.

( ) Yes, a great deal.

5
2
4
7
0
9
21
0

4) Do you prefer the monthly evaluations to be conducted as four or five activities in the classroom, as traditional exams or as another type of evaluation?

$\begin{array}{lc}\text { ( ) I prefer four or five activities in the classroom. } & 24 \\ \text { ( ) I prefer a traditional exam. } & 6 \\ \text { ( ) I prefer another type of evaluation. (Describe such an evaluation below). } & 13\end{array}$

5) After we discussed the use of Excel in the course, did you have difficulty performing the calculations in the requested activities?

$\begin{array}{lr}\text { ( ) No. } & 29 \\ \text { ( ) A little. } & 12 \\ \text { ( ) Yes, a great deal. } & 0\end{array}$

6) Did you have difficulty understanding the basics because we began with transient problems and then, moved to steady-state problems?

( ) No.
( ) A little.
() Yes, a great deal.

7) Do you prefer the course to begin with transient problems and then move to steady-state problems or vice versa? Or do you prefer another option?

( ) I prefer that it begin with transient problems.

( ) I prefer that it begin with the steady state.

( ) I prefer that it begin in another way. (Describe how this part of the course should be conducted below).

8) Did you have any difficulty understanding the heat transfer course? Mark the possibilities that apply.

( ) I understand the basics of the course well.

( ) I understand the physical sense of the problems well.

( ) I am able to connect the basics by solving a specific problem.

( ) I do not have a good understanding of the basics.

( ) I do not have a good understanding of the physical sense of the problems.

( ) I am not able to connect the basics by solving a specific problem.

$59 \%$ of the students preferred that the course began with transient problems, but in $2016.1,63 \%$ of the students would have preferred to begin with steady-state problems. Of the 41 students who responded to the questionnaire, on average, $41 \%$ preferred to begin with transient problems and $51 \%$ preferred to begin with the steady state. Perhaps the change in the preference for beginning with transient or steady-state problems is related to the practice of most books and professors of beginning with steady-state problems. In addition, it is possible that there could be an initial impact when the course begins with transient problems. In any event, we started with a simple transient problem to try to reduce the "in- 
itial shock" that we caused in the students. After the students became accustomed to the methodology, we believed that "it would seem natural" to them to start with transient problems.

Stammitti (2013) updated the teaching and learning experiences of students in the transport phenomena laboratory. His goal was achieved by using computers with Excel spreadsheets and without requiring students to acquire programming skills to use the spreadsheets. In the present investigation, our students created their own Excel spreadsheets, but when it was necessary, we preferred them to write or adapt Fortran programs instead of using commercial simulators. One of our goals is for students to know how to program in Fortran even though commercial simulators are available on the market. In general, we use Imsl subroutines and hope they continue to be available despite their cost; otherwise, we will employ similar subroutines that are free to use. Sometimes, we compare our calculations with those in books or articles, some of which were performed with commercial simulators.

According to Stammitti (2013), most students felt comfortable with the Excel environment after the laboratory sessions, and only $30 \%$ required assistance with the spreadsheets. In the present investigation, on average, 59\% of the students did not have difficulty calculating microscopic transient balances and $46 \%$ did not have difficulty performing steady-state calculations.

According to his webpage, Lund (2016) came to the conclusion presented next. Based on the students' performance and his observations, he found that they preferred the method he proposed.

In the present study, on average, $59 \%$ of the students preferred to perform four or five classroom activities per month. Cartaxo, Silvino, \& Fernandes (2014) asked, in question (5) of their questionnaire, "was the activity more interesting and motivating than the usual methods (exams) used in the course?" They considered the personal motivation of the students to be verified with question (5), to which $82 \%$ of the students responded positively to the use of the approach used in the lectures, which was "learning by doing". We posed a similar question in the present investigation: "Do you prefer four or five activities, or a traditional monthly exam?" On average, 59\% of the students preferred to perform all the activities in the classroom.

Question (7) of Regalado-Méndez, Cid-Rodríguez, \& Báez-González (2010) is related to the present study. The question is "Do you understand all the concepts?"; the possible answers were "Yes" and "No". According to RegaladoMéndez, Cid-Rodríguez, \& Báez-González (2010), 80\% of the students understood the basics. On average, only $32 \%$ of our students understood the basics of heat transfer basics well. This is an unsatisfactory and worrying result; we must change the methodology to improve our teaching and ensure that students become "captivated by the learning process" and that they improve their performance.

According to Ganley (2015), the student feedback regarding the homogeneous kinetics lab-oratory module has been generally very positive. The students' attitudes, answers in the module and dedication indicate satisfaction with the activi- 
ties. In Heat Transfer, 59\% of our students preferred to perform all the activities in the classroom.

We did not include questions about the reasons for which students preferred to perform all the activities in the classroom on the questionnaire, but we are convinced of the following:

1) Students chose the option to perform all the classroom activities because they were satisfied and almost free of stress and because the activities seemed easier than traditional exams.

2) They seemed to enjoy working in pairs, and perhaps, that will contribute to their professional futures, by decreasing the individualism that sometimes prevails in engineering careers.

3) We promoted "forced study in the classroom" with fewer demands than traditional exams have, but the students were able to comfortably perform almost all the activities.

4) Did the learning become more difficult because the students performed an activity on the same day that a topic was discussed? Apparently, this did not harm the learning. In addition, sometimes, we repeated an activity and subject to review the knowledge and to try to fill any gaps.

5) Students had fun, learned and received feedback on their knowledge in the heat transfer course, as we did.

Items from (1) to (5) mentioned before will be the object of our future research in the subject Heat Conduction.

\section{Conclusion}

The main conclusions we draw by analyzing and discussing the students' responses to the questionnaire are as follows:

1) The students had little difficulty in understanding the theory covered in Heat Transfer and had no difficulty calculating microscopic transient balances.

2) They preferred in-class activities to traditional monthly exams.

3) The students had little difficulty in understanding the basics because we began with transient problems and then moved on to steady-state problems.

4) Preference to start with either transient or steady state problems is greatly divided among students.

\section{References}

Akker, H. V., \& Mudde, R. F. (2014). Transport Phenomena: The Art of Balancing. Delft: Delft Academic Press.

Bird, R. B., Stewart, W. E., \& Lightfoot, E. (2002). Transport Phenomena. New York: Wiley.

Bird, R. B., Stewart, W. E., Lightfoot, E., \& Klingenberg, D. J. (2014). Introductory Transport Phenomena. New York: Wiley.

Carslaw, H. S., \& Jaeger, J. C. (1980). Conduction of Heat in Solids. Oxford: Oxford University Press.

Cartaxo, S. J. M., Silvino, P. F. G., \& Fernandes, F. A. N. (2014). Transient Analysis of Shell-and-Tube Heat Exchangers Using an Educational Software. Education for Chem- 
ical Engineering, 9, e77-e84. https://doi.org/10.1016/j.ece.2014.05.001

Crank, J. (1976). The Mathematics of Diffusion. Oxford: Clarendon Press.

Cutlip, M. B., \& Shacham, M. (1999). Problem Solving in Chemical Engineering with Numerical Methods. London: Prentice Hall.

Ganley, J. C. (2015). A Homogeneous Chemical Reactor Analysis and Design Laboratory: The Reaction Kinetics of Dye and Bleach. Education for Chemical Engineering, 12, 20 26. https://doi.org/10.1016/j.ece.2015.06.005

Komulainen, T. M., Enemark-Rasmussen, R., Sin, G., Fletcher, J. P., \& Cameron, D. (2012). Experiences on Dynamic Simulation Software in Chemical Engineering Education. Education for Chemical Engineering, 7, e153-e162.

https://doi.org/10.1016/j.ece.2012.07.003

Luikov, A. V. (1968). Analytical Heat Diffusion Theory. New York: Academic Press.

Lund, C. R. F. (2008). A Text for Engineering Education in the 21st Century 1. Objectives and Overview. In ASEE-American Society for Engineering Education, Proceedings of the 2008 Annual ASEE Conference. Paper AC-2008-192 (13.126.1-13.126.11). Pittsburgh, PA.

Lund, C. R. F. (2009). A Text for Engineering Education in the 21st Century 2. A Sample Study Unit. In ASEE-American Society for Engineering Education, Proceedings of the 2009 Annual ASEE Conference. Paper AC 2009-612 (14.132.1-14.132.11). Austin, TX.

Lund, C. R. F. (2016). A First Course on Kinetics and Reaction Engineering. http://wwwresearch.sens.buffalo.edu/karetext/title/title.shtml

Regalado-Méndez, A., Cid-Rodríguez, M. R. P., \& Báez-González, J. G. (2010). Problem Based Learning (PBL): Analysis of Continuous Stirred Tank Chemical Reactors with a Process Control Approach. International Journal of Software Engineering\& Application, 1, 54-73. https://doi.org/10.5121/ijsea.2010.1404

Regalado-Méndez, A., Peralta-Reyes, E., \& Báez-González, J. G. (2011). CompetencyBased Learning Applied to a Heat Transfer Course. Formación Universitaria, 4, 13-18. https://doi.org/10.4067/S0718-50062011000100003

Sadiku, M. N. O., \& Obiozor, C. N. (2000). A Simple Introduction to the Method of Lines. International Journal of Electrical Engineering Education, 37, 282-296. https://doi.org/10.7227/IJEEE.37.3.8

Schiesser, W. E., \& Silebi, C. A. (2009). Computational Transport Phenomena: Numerical Methods for the Solution of Transport Problems. Cambridge: Cambridge University Press.

Slattery, J. C. (1999). Advanced Transport Phenomena. Cambridge: Cambridge University Press. https://doi.org/10.1017/CBO9780511800238

Spiegel, M. R., Lipschutz, S., \& Liu, J. (2009). Mathematical Handbook of Formulas and Tables. New York: McGraw-Hill.

Stammitti, A. (2013). Spreadsheets for Assisting Transport Phenomena Laboratory Experiences. Education for Chemical Engineering, 8, e58-e71. https://doi.org/10.1016/j.ece.2013.02.005

Vega, F., Portillo, E., Cano, M., \& Navarrete, B. (2014). Teaching Experiences in Chemical Engineering: Design, Manufacturing and Start-Up of a Lab-Scale Distillation Unit Using Problem-Based Learning. Formación Universitaria, 7, 13-22. https://doi.org/10.4067/S0718-50062014000100003

Welty, J. R., Wickes, C. E., \& Wilson, R. E. (1969). Fundamentals of Momentum, Heat and Mass Transfer. New York: Wiley.

Wouwer, A. V., Saucez, P., \& Vilas, C. (2014). Simulation of PDE/ODE Models with $M A T L A B, O C T A V E$ and SCILAB. Cham: Springer. 
Submit or recommend next manuscript to SCIRP and we will provide best service for you:

Accepting pre-submission inquiries through Email, Facebook, LinkedIn, Twitter, etc. A wide selection of journals (inclusive of 9 subjects, more than 200 journals)

Providing 24-hour high-quality service

User-friendly online submission system

Fair and swift peer-review system

Efficient typesetting and proofreading procedure

Display of the result of downloads and visits, as well as the number of cited articles Maximum dissemination of your research work

Submit your manuscript at: http://papersubmission.scirp.org/

Or contact ce@scirp.org 